\title{
AWARENESS ABOUT APPROPRIATE PRACTICE OF SODIUM POLYSTYRENE SULFONATE ADMINISTRATION.
}

1. MBBS, FCPS, FRCP

Professor

Fatima Memorial Hospital, Lahore.

2. MBBS

Post Graduate Resident

Fatima Memorial Hospital, Lahore.

3. MBBS

Post Graduate Resident

Fatima Memorial Hospital, Lahore.

Correspondence Address:

Dr. Rizwana Kitchlew

Professor

Fatima Memorial Hospital, Lahore.

riz102403@yahoo.com

Article received on:

28/01/2019

Accepted for publication:

$21 / 05 / 2019$

\begin{abstract}
Rizwana Kitchlew' ${ }^{1}$, Miqdad Haider ${ }^{2}$, Saba Mir ${ }^{3}$
ABSTRACT: In patients of Chronic Kidney Disease (CKD) one of the most frequent and threatening complication is hyperkalemia. Sodium polystyrene sulfonate (SPS) commonly known as Kayexalate is one of the treatment options in management of hyperkalemia. Food and Drug Authority (FDA) has recently issued a warning that SPS is not to be administered at the same time with other oral drugs. Objectives: To assess the prevailing concepts about Sodium Polystyrene Sulfonate administration and its interactions with other drugs among doctors and patients. Study Design: A Descriptive study. Setting: Three Tertiary Care Health Centers of Lahore. Period: 1st January 2018 till 31st July 2018. Material \& Methods: The study population includes adult patients who had suffered from hyperkalemia, and the doctors who have been prescribing the drug and gave consent to participate in the survey. The statistical analysis was performed on SPSS version 23. Results: The total number of study participants were 75, where 50 were doctors and 25 were patients receiving Kayexalate treatment. The age range for doctors was between 24 to 55 years with mean age of $31.4 \pm 7.2$ years. Among doctors 37 (74\%) prescribe SPS at some interval from other medications, whereas only $4(8 \%)$ prescribe at the interval recommended by FDA (3 hours). Only 19 (38\%) said they knew about the latest guidelines of FDA about SPS interaction with other drugs and $38(76 \%)$ had knowledge that SPS hampers absorption of other drugs. Among population comprising of patients receiving kayexalate, the age range was between 27 to 68 years with mean age of $49.2 \pm 8.5$ years. 11 (44\%) patients were advised to take this drug at some interval from other drugs. Conclusion: Hyperkalemia is commonly seen in tertiary care setups, especially in CKD patients. Kayexalate being an affordable option for its treatment, there is a need for improvement in training of doctors about its use and its interactions with food and other medications.
\end{abstract}

Key words: Chronic Kidney Disease, Hyperkalemia, Kayexalate, Sodium Polystyrene Sulfonate.

Article Citation: Kitchlew R, Haider M, Mir S. Awareness about appropriate practice of Sodium Polystyrene Sulfonate administration. Professional Med J 2020; 27(1):52-56. DOI: 10.29309/TPMJ/2020.27.1.3184

\section{INTRODUCTION}

Chronic kidney disease (CKD) is a condition characterized by a gradual loss of kidney function over time. Its prevalence is increasing in South Asian countries like Pakistan, and the reason behind this spread can be attributed to various factors including lack of education, economic crisis on national level, poor healthcare services and increasing prevalence of chronic diseases like Diabetes and Hypertension. Hyperkalemia is one of the common complication in CKD patients and a potential threat to patient safety. Causes of hyperkalemia include increased intake, reduced renal excretion or a shift from intracellular space. Dietary components rich in potassium include banana, pineapple, dates, potatoes, beans, dried fruits and others. Hyperkalemia can be graded as mild (5.5-6.5 mmol/l), moderate (6.5-7.5 mmol/l) and severe (>7.5 mmol/l). ${ }^{1}$

For treatment, calcium gluconate, insulin with dextrose, Beta adrenergic agonists, Resins and Dialysis are possible options. Sodium polystyrene sulfonate (SPS) is a sulfonated salt generally known as kayexalate found in powdered form which is used to treat hyperkalemia especially in patients of CKD. It was first approved by FDA in $1958 .{ }^{2}$ Recently a question has been raised regarding its potential of adhering with other drugs ingested simultaneously and thus affecting 
their absorption. Since patients of CKD are often on multiple drugs at a time which are vital for them therefore very recently FDA has issued a warning that SPS is not to be administered at the same time with other oral drugs. An interval of minimum 3 hours is recommended. ${ }^{3}$

This time should be increased to 6 hours for patients with gastro paresis or other conditions resulting in delayed emptying of food from stomach to small intestine. This drug delays absorption of vital drugs such as Amlodipine, Furosemide, Metoprolol, Amoxicillin, Phenytoin, Warfarin, Levothyroxine and Lithium. ${ }^{4}$

\section{OBJECTIVES}

To assess the prevailing concepts about Sodium Polystyrene Sulfonate administration and its interactions with other drugs among doctors and patients and to give awareness about its proper use.

\section{METHODOLOGY}

This cross-sectional, descriptive study was conducted in three tertiary care health centers in the city of Lahore during January 2018 to July 2018.

Patients of 18 years or more of age, who had suffered from hyperkalemia and the doctors who have been prescribing the drug and gave consent to participate in the survey were included in the study. Doctors and patients who gave partial answers as per the questionnaires were excluded. A survey was completed by 50 doctors who were familiar with the use of SPS and another one was completed by 25 patients who have been prescribed the drug, over a period of 6 months. Doctors were asked to complete selfadministered pre-validated questionnaires.

However the patients were assisted by the researcher to fill in the questionnaire from their record documents. Data from these surveys was used to assess and provide awareness to patients and doctors about Sodium Polystyrene Sulfonate administration.
Both questionnaires were developed in English. Questions addressed the prevailing pathologies in patients, usual drug intake, dosage, plus, the dose, frequency, interval from other drugs and duration of Kayexalate administration. Each question included multiple options. Doctors were also asked about effect of Kayexalate on absorption of other drugs and about FDA recommendations regarding its use.

Ethical approval was obtained from the Institutional Review Board (IRB). All participants were informed about the study and were told that their participation was voluntary and it was assured to them that their participation will be kept anonymous.

Statistical Package of Social Science (SPSS Inc., Chicago, IL) for Windows version 23.0 was used for data analysis. A p-value of $<0.05$ was considered statistically significant.

\section{RESULTS}

The total number of study participants were 75 , where 50 were doctors and 25 were patients receiving Kayexalate treatment.

Among doctors there were 29 (58\%) males and $21(42 \%)$ females. 13 were from the department of Nephrology while 37 were from Department of medicine. The age range was between 24 to 55 years with mean age of $31.4 \pm 7.2$ years. 37 doctors $(74 \%)$ prescribe SPS at some interval from other medications, whereas only 4 (8\%) prescribe at the interval recommended by FDA (3 hours) in their daily practice of management of hyperkalemia. (38\%) said they knew about the latest guidelines of FDA about SPS interaction with other drugs. $38(76 \%)$ had knowledge that SPS hampers absorption of other drugs.

Comparison between the response from physicians and nephrologists for questions regarding Kayaxelate use is shown in the Table-l. The Table-II presents the knowledge of doctors regarding Kayexalate interaction with commonly used drugs. 


\begin{tabular}{|c|c|c|c|c|c|c|}
\hline \multirow{2}{*}{$\begin{array}{l}\text { Sr. } \\
\text { No }\end{array}$} & \multirow[t]{2}{*}{ Question } & \multicolumn{2}{|c|}{$\begin{array}{l}\text { Nephrologist } \\
\quad(n=13)\end{array}$} & \multicolumn{2}{|c|}{$\begin{array}{l}\text { Other Physicians } \\
\qquad(n=37)\end{array}$} & \multirow[t]{2}{*}{ P-Value } \\
\hline & & Yes & No & Yes & No & \\
\hline 1. & $\begin{array}{l}\text { Are you aware that Kayexalate hampers } \\
\text { absorption of some drugs? }\end{array}$ & 12 (92\%) & $1(7.7 \%)$ & 26 (70.3\%) & $11(29.7 \%)$ & 0.107 \\
\hline 2. & $\begin{array}{l}\text { Do you prescribe ingestion of this medicine at } \\
\text { interval from other medications? }\end{array}$ & $10(77 \%)$ & 3 (23\%) & 27 (73\%) & $10(27 \%)$ & 0.547 \\
\hline 3. & $\begin{array}{l}\text { Are you aware that FDA has recommended } \\
3-6 \text { hrs interval administration from other oral } \\
\text { drugs? }\end{array}$ & $4(31 \%)$ & $9(69 \%)$ & 15 (40.5\%) & 22 (59.5\%) & 0.390 \\
\hline
\end{tabular}

Table-I. Comparison of answers from Nephrologist and General Doctors.

\begin{tabular}{|c|c|c|c|c|c|c|}
\hline \multirow{2}{*}{ Sr. No } & \multirow{2}{*}{ Drug } & \multicolumn{2}{|c|}{ Nephrologist $n=13$} & \multicolumn{2}{|c|}{ Other Physicians $n=37$} & \multirow{2}{*}{ P-Value } \\
\hline & & Yes & No & Yes & No & \\
\hline 1. & Amlodipine & $4(31 \%)$ & $9(69 \%)$ & $9(24 \%)$ & $28(76 \%)$ & 0.402 \\
\hline 2. & Metoprolol & $1(7.7 \%)$ & 12 (92.3\%) & 7 (19\%) & $30(81 \%)$ & 0.321 \\
\hline 3. & Frusemide & $1(7.7 \%)$ & 12 (92.3\%) & $12(32 \%)$ & $25(68 \%)$ & 0.078 \\
\hline 4. & Phenytoin & $2(15 \%)$ & $11(85 \%)$ & $13(35 \%)$ & $24(65 \%)$ & 0.163 \\
\hline 5. & Warfarin & $4(31 \%)$ & $9(69 \%)$ & $10(27 \%)$ & $27(73 \%)$ & 0.529 \\
\hline 6. & Levothyroxin & $0(0 \%)$ & $13(100 \%)$ & $5(13.5 \%)$ & $32(86 \%)$ & 0.206 \\
\hline 7. & Lithium & $2(15 \%)$ & $11(85 \%)$ & $6(16 \%)$ & 31 (84\%) & 0.659 \\
\hline
\end{tabular}

Table-II. Knowledge of doctors regarding interaction of Kayexalate with commonly used drugs

Among population comprising of patients receiving kayexalate, there were 11 (44\%) males and $14(56 \%)$ females. The age range was between 27 to 68 years with mean age of 49.2 \pm 8.5 years. $23(92 \%)$ had CKD, $16(64 \%)$ were diabetics and 19 (76\%) were hypertensives. Among them 20 (80\%) were receiving Furosemide, while warfarin and phenytoin were used by 1 patient each, 3 were on levothyroxine. 10 (40\%) were experiencing gastro paresis. Laxatives were being used along with SPS in 20 (80\%) patients. Only 2 (8\%) patients reported diarrhea. 11 (44\%) patients were advised to take this drug at some interval from other drugs, while actually 13 (52\%) patients took the drug at an interval of 3 hours or more from other drugs.

\section{DISCUSSION}

In the US for over 50 years the only potassium binder that was available was sodium-polystyrene sulfonate and calcium-polystyrene sulfonate was available in some other countries. It was mainly used in the context of acute hyperkalemia. ${ }^{5}$ It should not be considered an emergency intervention, as its onset of action is after several hours following oral administration. ${ }^{6}$ It should only be used in emergency situations in conjunction with other interventions with shorter onset of action. Fordjour $\mathrm{KN}^{9}$ reported Oral SPS monotherapy was the predominant treatment for hyperkalemia with the best response at the highest dose. Kessler $\mathrm{C}^{10}$ et al reported that the mean potassium concentration decreased by 0.82 to $1.40 \mathrm{mmol} / \mathrm{L}$ depending on dose used.

Among our study subjects we found that majority (76\%) of the doctors though familiar with its use were not aware of the fact that simultaneous administration with which vital drugs in such patients leads to malabsorption of these drugs. The majority prescribing Kayexelate did not know the safe interval of ingestion from other drugs. We compared the group of doctors working in nephrology units with other physicians and found no significant difference regarding this drug administration practice among the two groups.

The patients assessed also showed lack of information about appropriate administration interval. The $44 \%$ who were observing interval ingestion from their other medications were not adequately counselled in this respect. This 
probably is due to lack of information on the part of prescribing physician. Though the sample size of our study was small however the results show that the physicians are still not aware of the latest warnings issued by FDA in June 2017 regarding Kayexelate use. SPS can lead to malabsorption of drugs like furosemide, metoprolol and amlodipine which are commonly included in the prescription of a patient with renal failure and form very important component of management. This can lead to inefficacy in treatment.

The new Potassium lowering drugs Patiromer ${ }^{11}$ and sodium zirconium cyclosilicate ${ }^{12}$ being expensive plus their non-availability in Pakistan still makes SPS as one of the management option for hyperkalemia. Therefore we emphasize that clinicians prescribing this medicine must be apprised of not only appropriate method, dose, route of administration plus also about precautions required for interval administration from other vital drugs as it can hamper their absorption leading to loss of their effect and adversely affecting the patient.

\section{CONCLUSION}

Awareness about Kayexalate interaction with food and other medications among general physicians is still not sufficient. Doctors working in department of Nephrology have a better understanding about this subject, however even they need to be briefed about latest recommendations of FDA.

\section{Copyright@ 21 May, 2019.}

\section{REFERENCES}

1. Inker LA, Astor BC, Fox CH, Isakova T, Lash JP, Peralta CA, Tamura MK, Feldman HI. KDOQI US commentary on the 2012 KDIGO clinical practice guideline for the evaluation and management of CKD. American Journal of Kidney Diseases. 2014 May 1; 63(5):713-35.

2. SPS Suspension (sodium polystyrene sulfonate suspension, USP) prescribing information. Farmville, North Carolina: Carolina Medical Products Company; Mar, 2011. Available at: http://dailymed.nlm.nih.gov/ dailymed/druglnfo.cfm?setid=12d48dcf-07bd-4b06bd6c-7543f1be8357. Accessed September 25, 2015.
3. Food and drug administration safety: Kayexelate (sodium polystyrene sulfonate powder. Feb 17, 2011. Available at: http://www.fda.gov/Safety/MedWatch/ Safetylnformation/ucm186845.htm. Accessed May 21, 2015.

4. Harel Z, Harel S, Shah PS, Wald R, Perl J, Bell CM. Gastrointestinal adverse events with sodium polystyrene sulfonate (Kayexalate) use: A systematic review. The American journal of medicine. 2013 Mar 1; 126(3):264-e9.

5. McGowan CE, Saha S, Chu G, Resnick MB, Moss SF. Intestinal necrosis due to sodium polystyrene sulfonate (Kayexalate) in sorbitol. South Med J. 2009; 102(5):493-7.

6. Nguyen T, Ondrik D, Zhufyak O, To W, He S. Hyperkalemia and potential pitfalls of sodium polystyrene sulfonate. JAAPA. 2015 Mar; 28(3):41-5.

7. Chaitman M, Dixit D, Bridgeman MB. PotassiumBinding Agents for the Clinical Management of Hyperkalemia. P T. 2016; 41(1):43-50.

8. FDA drug safety communication [Internet]. U.S food and drug administration. 2017 [cited 26 September 2018]. Available from: https://www.fda.gov/Drugs/ DrugSafety/ucm572484.htm

9. Fordjour KN, Walton T, Doran J. Management of hyperkalemia in hospitalized patients. Am $\mathrm{J}$ Med Sci. 2014; 347:93-100. [PubMed].

10. Kessler $\mathrm{C}, \mathrm{Ng} \mathrm{J}$, Valdez $\mathrm{K}$, et al. The use of sodium polystyrene sulfonate in the inpatient management of hyperkalemia. J Hosp Med. 2011; 6:136140. [PubMed].

11. Patiromer (Veltassa) for the treatment of hyperkalemia: Overview. https://www.ncbi.nlm.nih. gov/books/NBK525778/.

12. David K. Packham M.B, Henrik S. Rasmussen et al sodium zirconium cyclosilicate in hyperkalemia. January 15, 2015N Engl J Med 2015; 372:222-23. 


\begin{tabular}{|c|l|l|l|}
\hline \multicolumn{3}{|c|}{ AUTHORSHIP AND CONTRIBUTION DECLARATION } \\
\hline Sr. \# & Author(s) Full Name & \multicolumn{1}{|c|}{ Contribution to the paper } & Author(s) Signature \\
\hline 1 & Rizwana Kitchlew & $\begin{array}{l}\text { Concepualization of study design, } \\
\text { Data analysis, Data interpretation, } \\
\text { Write-up, Proof reading. } \\
\text { Literature search, Data collection, } \\
\text { Data analysis, Write up. } \\
\text { Literature search, Data collection \& } \\
\text { analysis. }\end{array}$ \\
\hline 3 & Saba Mir & Miqdad Haider & \\
\hline
\end{tabular}

